Arch. histol. jap., Vol. 45, No. 1 (1982)

p. $37-44$

\title{
A Light Microscopic Demonstration of Amoeboid Microglia and Microglial Cells in the Retina of Rats of Various Ages*
}

\author{
E. A. LING \\ Department of Anatomy, Faculty of Medicine, National University of Singapore, Singapore
}

Received February 16, 1981

\begin{abstract}
Summary. The retinae from rats of various ages were stained using the weak silver carbonate method of del Rio-Hortega. In newborn and early postnatal (3-day-old) rats, silverimpregnated round and amoeboidic cells displaying thick stout pseudopodial processes were distributed in the nerve fiber and ganglion cell layers. In 10-day-old rats, the cell bodies were rod-shaped bearing pseudopodia or fusiform showing slender and branching processes. The majority of the cells were found in the ganglion cell layer with occasional ones in the inner plexiform layer. By 20 days of age, the cells became smaller and exhibited long branching processes. They were located predominantly in the inner plexiform or bipolar cell layer. In the adult animals, all the silver-impregnated cells appeared small and flattened with long branching processes. Based on their morphological features, it was concluded that they were in fact amoeboid microglia and microglial cells present in the developing retina which probably function as macrophages as described in the brain tissues.
\end{abstract}

The presence of macrophages in the postnatal retina has been described both histochemically (SANYAL, 1972) and electron microscopically (OLNEY, 1968; LING, 1981a). In the retina of postnatal rats (LING, 1981a) the majority of these cells displayed ultrastructural features of amoeboid microglia (also referred to as amoeboid cells by Імамото and LEBLOND, 1978) which were macrophages in the subcortical white matter in the developing brain (LING, 1981b); a few, on the other hand, were endowed with features typical of microglia. Since amoeboid microglia and microglial cells in the brain were known to stain specifically with the weak silver carbonate stain of del Rio-Hortega (LING, 1976), the same method was therefore applied to the retina to ascertain their existence in this tissue. Moreover, evidence accumulated over the past years (Ling, 1981b) has shown that the numerous amoeboid microglial cells in the brain of newborn animals gradually diminish with age and are subsequently transformed into microglial cells which are absent at birth. The second aim of the present study was to find out whether these cells, if they were to be present in the retina, followed the same developmental pattern as in the brain.

*This study was kindly supported by a grant from the Singapore Turf Club. 


\section{MATERIALS AND METHODS}

The eyes from Wistar rats of different age groups ranging from newborn to 5 months were freshly removed under ether anaesthesia. They were then fixed in toto in formaldehyde-ammonium bromide solution for 10-14 days. Sagittal frozen sections at $30 \mu \mathrm{m}$ were prepared and stained in del Rio-Hortega's silver carbonate method for microglia.

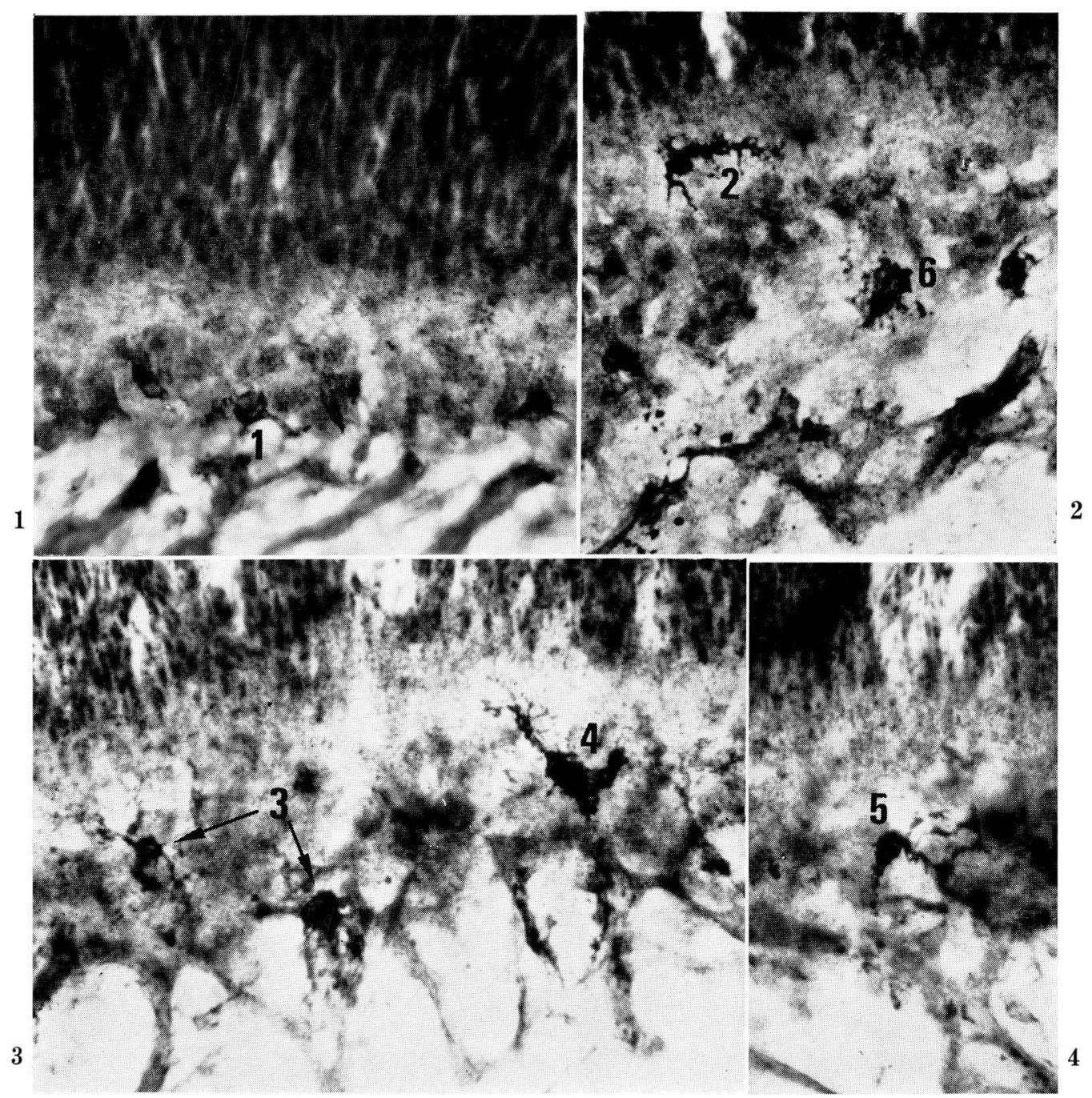

Fig. 1-4. Amoeboid microglial cells in the nerve fiber and ganglion cell layers in the retina of newborn (Fig. 1, 2) and 3-day-old (Fig. 3, 4) rats. The cells range from round (1) to cells which are amoeboidic form bearing pseudopodia $(2,3)$. Arising from the pseudopodia are secondary processes bearing expanded terminals $(4,5)$. Some cells show short spinous processes $(6)$. The bipolar cell layer is orientated to the top of the figures. $\times 440$ 


\section{OBSERVATIONS}

In the retina of newborn and 2 to 3 -day-old rats, a variable number of cells were positively stained with the weak silver carbonate method of del Rio-Hortega. These cells were distributed predominantly in the nerve fiber and ganglion cell layers. In the nerve fiber layer, they were widely scattered in the vascular meshwork. The cells were pleomorphic, ranging from round to amoeboidic form sending out three to five pseudopodia-like thick stout cytoplasmic processes which in turn gave rise to some short secondary processes (Fig. 1-4).

By ten days of age, the layers in the retina were well demarcated. The silverimpregnated cells in the nerve fiber layer showed a rod-shaped or elongated cell body. However, just as in the younger animals they displayed broad cytoplasmic processes often resting on the perivascular walls (Fig. 5). Numerous silver-positive cells were also seen in the ganglion cell layer but their cell bodies were mainly fusiform (Fig. 6). Their long and slender processes which were located at both poles extended into the inner plexiform and nerve fiber layers (Fig. 6). Occasional silver-impregnated cells appeared to have invaded the inner plexiform layer at this age (Fig. 7).

At weaning age (20 days), the majority of the silver-impregnated cells were located in the inner plexiform or at the border area between the inner plexiform and bipolar cell layers (Fig. 8-10). Their cell bodies were often embedded in the bipolar cell layer whereas their long branching cytoplasmic processes penetrated deeply into the inner plexiform layer (Fig. 9, 10). These processes sometime measured approximately $40 \mu \mathrm{m}$ in length. Perpendicular to the main cytoplasmic prolongations were some fine secondary processes (Fig. 10).

There were no apparent changes in the distribution of the silver-impregnated cells in the older animals (over 3 months of age). However, there were fewer impregenated cells per section profile as compared to the retina of the younger ages. The majority of the cells encountered were located in the inner plexiform layer or at its border with the bipolar cell layer. The cells showed a stellate or fusiform body giving rise to three to five profusely branched cytoplasmic processes (Fig. 11-13).

So far silver-impregnated cells have not been observed in the outer plexiform nor in the receptor cell layer.

\section{DISCUSSION}

Since developmentally the retina is an evagination of the brain, it was reasoned that it should contain cellular elements as a counterpart of the microglial cells in the brain tissues. Indeed, with the silver carbonate method of del Rio-Hortega, the presence of microglial cells in the inner layers of the retina was demonstrated. Despite their pleomorphism, it is possible to generalize that in the retinae of newborn and early postnatal rats, the cells were mostly of the round or amoeboidic form showing pseudopodial processes. However, as the animals aged, the cell bodies became progressively smaller and they assumed an elongated form giving rise to long and fine branching processes.

The round or amoeboidic silver-impregnated cells present in the newborn and early postnatal retina were similar to the amoeboid microglial cells in developing brain (LiNG, 1976). Based on their distribution and external morphology, they appeared to correspond to the large retinal macrophages under the electron microscope (LiNG, 1981a). 

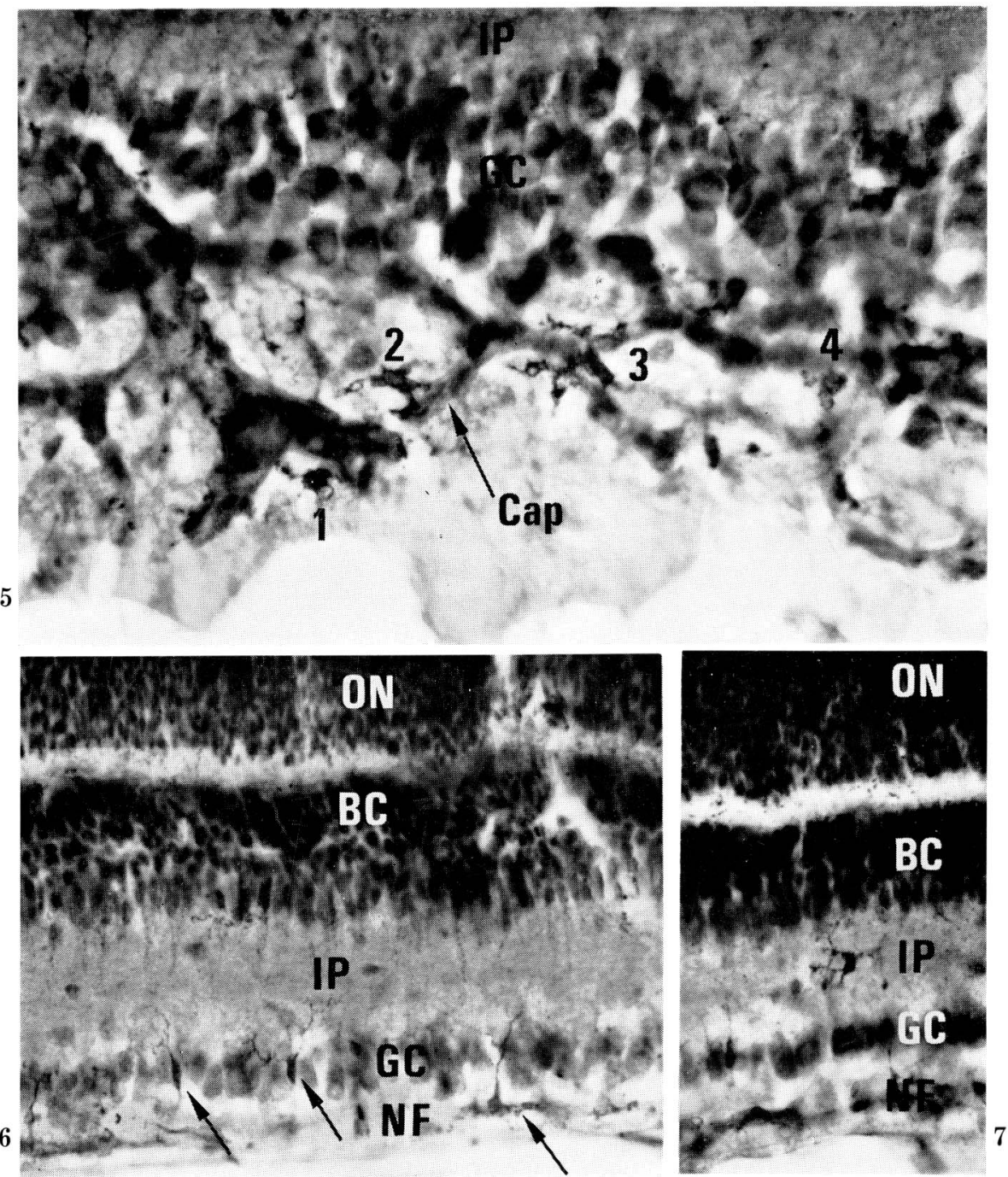

Fig. 5. A tangential section of the nerve fiber layer (lower half of the figure) in the retina of a 10-day-old rat. Four amoeboid microglial cells which are numbered are closely related to the capillary network $(\mathrm{Cap})$; one of the cells has its broad processes extending to the capillary wall (arrow). These cells which are rodliked are considered to be the intermediate type between the amoeboidic form in the early postnatal rats and the fusiform cells in Figures 6 and 7 . GC ganglion cell layer, IP inner plexiform layer. $\times 440$

Fig. 6. Three fusiform microglial cells (arrows) in the ganglion cell layer $(G C)$ in a 10day-old rat. Their long branching processes penetrate the inner plexiform layer $(I P)$. The cell on the right has its cell body in the nerve fiber layer $(N F)$ but its long slender process spans the ganglion cell layer. $B C$ bipolar cell layer, $O N$ outer nuclenr layer. $\times 440$

Fig. 7. A silver-impregnated microglial cell in the inner plexiform layer $(I P)$ of the retina in a 10-day-old rat. The ramifying cytoplasmic processes arise from one side of the cell. This cell is considered to be the intermediate form between those in Figures 5 and 6 . Note the well-demarcated layers of retina at this age. $B C$ bipolar cell layer, $G C$ ganglion cell layer, $N F$ nerve fiber layer, $O N$ outer nuclear layer. $\times 275$ 


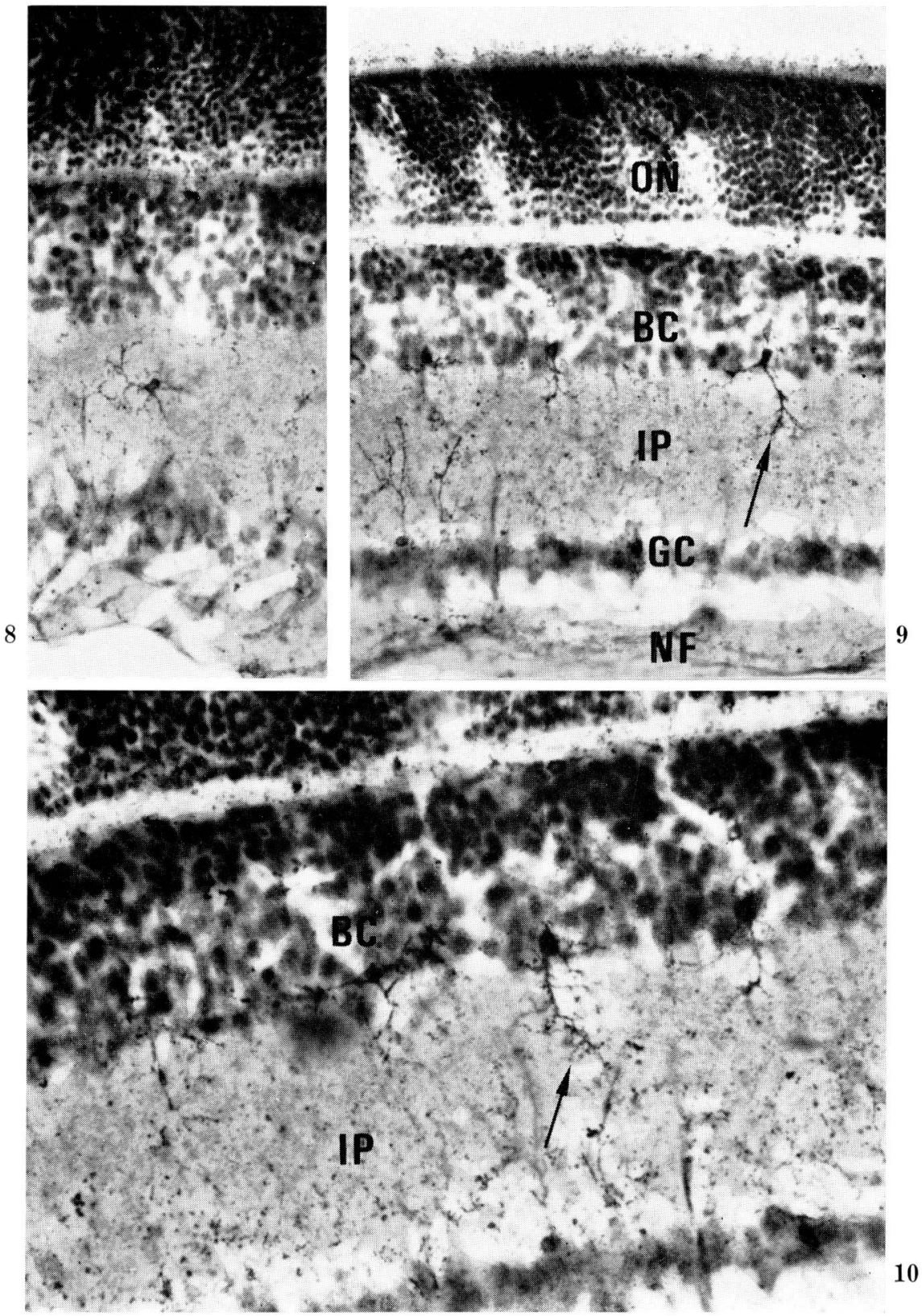

Fig. 8. A microglial cell in the inner plexiform layer in a 20-day-old rat. $\times 275$

Fig. 9 and 10. At least three silver-impregnated microglial cells are seen in the border area between the inner plexiform $(I P)$ and bipolar cell $(B C)$ layer in a 20-day-old rat. They show long processes (arrow) ramifying in the inner plexiform layer. GC ganglion cell layer, $N F$ nerve fiber layer, $O N$ outer nuclear layer. Fig. 9: $\times 275$, Fig. 10: $\times 440$ 
The small flattened cells with branching processes which were preponderant in the retina of older animals were identical to the microglial cells in the brain (MoRI and Leblond, 1969). For comparison, a microglial cell stained with a similar method is

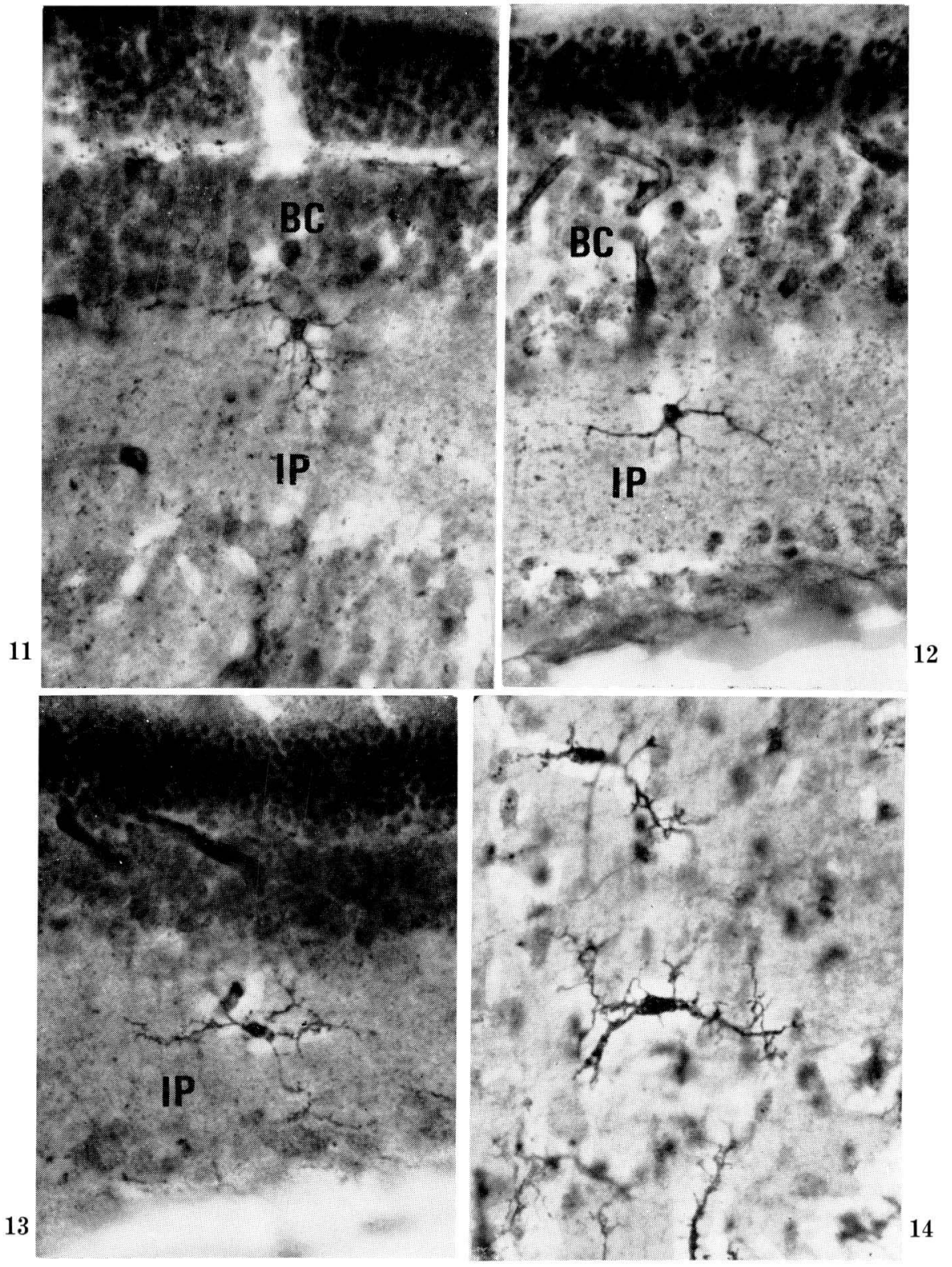

Fig. 11-13. Microglial cells in the inner plexiform $(I P)$ and at its border with the bipolar with the bipolar cell layer $(B C)$ in the retina of a 3 -month (Fig. 11) and a 5 -month (Fig. 12, 13) rat. They show profuse cytoplasmic branchings. The cell in Figure 13 is flattened and its processes extend from both poles of the cell. Compare with Figure $14 . \times 440$

Fig. 14. Two typically flattened microglial cells in the corpus callosum of a young adult rat. $\times 440$ 
presented in Figure 14. As a corollary to the microglial cells in the brain, the small flattened cells were absent in the newborn and early postnatal animals but gradually increased with age. with the silver method, they were indistinguishable from the microglia. It seems therefore justifiable to conclude that they were in fact microglial cells in the retina. They would correspond to the cells in the retina which were described as microglia-like under the electron microscope (LinG, 1981a).

The possibility of the transformation of retinal amoeboid microglia into retinal microglia was manifested in the 10-day-old rats where some cells showed thick stout processes, while others exhibited fine branching processes and still others intermediate features. It is speculated that in the course of retinogenesis, the round and amoeboidic microglial cells gradually transform into small flattened microglial cells just as in the brain tissues (LING, 1976). By weaning age, all the retinal microglial cells assume their adult form similar to the resting or sessile microglia in the brain (LiNG, 1981b).

In the newborn and early postnatal rats, the retinal amoeboid microglial cells were located in the ganglion cell and nerve fiber layers. The latter showed a rich capillary bed which may well be the source of origin of these cells, since it has been demonstrated that their counterpart amoeboid microglial cells in the brain were in fact invaded blood monocytes (Iмамото and Leblond, 1978). From the nerve fiber layer the amoeboid microglial cells probably migrated into the inner plexiform and thence into bipolar cell layers. In the course of their migration they tended to elongate and send out long cytoplasmic processes to become flattened microglial cells. It is perhaps relevant that the macrophages as reported by SANyAL and his colleagues (SANyAL, 1972; SAnYAL, De RUITER and HAwKINS, 1980) in the postnatal mice were found to spread from the central towards the outer layers in the growth of the retina.

The presence of amoeboid microglia and microglial cells in the course of retinogenesis may be related to the development and remodeling of the loosely organized postnatal neural tissues. Cell deaths have been reported to be rather common in retinal development (GlÜCKSMANN, 1951). With the electron microscope, sporadic degenerating cells were observed in the postnatal retina (LING, unpublished observation). In this connection, the large retinal macrophages resembling amoeboid microglia were probably in an active form since they often carried phagosomes (LING, 1981a). With growth, the neural tissues become more and more compact, the amoeboid microglial cells probably then regressing to the resting or dormant form, i.e. microglial cells in adult animals.

The absence of amoeboid microglia and microglial cells in the receptor layer may be due to the fact that phagocytic activity is performed by pigmented cells which have been demonstrated to phagocytose the outer segments of rod and cone cells in normal and experimental degeneration of retina (O'STEEN and KARCIOGLU, 1974).

Acknowledgements. The technical assistance of Miss Margaret Sim is gratefully acknowledged. Dr. A. S. CHAN kindly read the manuscript.

\section{REFERENCES}

Glücksmann, A.: Cell deaths in normal vertebrate ontogeny. Biol. Rev. 26: 59-86 (1951).

Imamoto, K. and C. P. Leblond: Radioautographic investigation of gliogenesis in the corpus callosum of young rats. II. Origin of microglial cells. J. comp. Neurol. 180: 139-164 (1978). 
Ling, E. A.: Some aspects of amoeboid microglia in the corpus callosum and neighbouring regions of neonatal rat. J. Anat. 121: 29-45 (1976).

: Ultrastructure and peroxidase cytochemistry of macrophages present in the retina of postnatal rats. Arch. histol. jap. 44: 167-176 (1981a).

- : The origin and nature of microglia. In: (ed. by) Fedoroff, S. and L. Hertz: Advances in cellular neurobiology Vol. II. Academic Press, New York, 1981b (p. 33-82).

Mori, S. and C. P. Leblond : Identification of microglia in light and electron microscopy. J. comp. Neurol. 135: 57-80 (1969).

Olney, J. W.: An electron microscopic study of synapse formation, receptor outer segment development, and other aspects of developing mouse retina. Invest. Ophthal. 7: 250-268 (1968).

O'Steen, W. K. and Z. A. Karcioglu : Phagocytosis in the light-damaged albino rat eye. Light and electron microscopic study. Amer. J. Anat. 139: 503-518 (1974).

Sanyal, S.: Changes of lysosomal enzymes during hereditary degeneration and histogenesis of retina in mice. II. Localization of N-acetyl-B-glucosaminidase in macrophages. Histochemie 29: 28-36 (1972).

Sanyal, S., A. De Ruiter and R. K. Hawkins : Development and degeneration of retina in rds mutant mice: Light microscopy. J. comp. Neurol. 194: 193-207 (1980).

Dr. E. A. Ling

Department of Anatomy

Faculty of Medicine

National University of Singapore

Sepoy Lines, Singapore 0316 